\title{
EFFICACY OF AN INACTIVATED VACCINE AGAINST CLINICAL DISEASE CAUSED BY CANINE CORONAVIRUS
}

\author{
R. Fulker, T. Wasmoen, R. Atchison, H-J. Chu, and W. Acree \\ Fort Dodge Laboratories \\ Fort Dodge, Iowa
}

\begin{abstract}
Canine Coronavirus (CCV) is a causative agent of diarrhea in dogs. The reproduction of severe clinical disease with experimental CCV infection has been difficult. We have recently developed a CCV challenge model which reproduced clinical signs of disease in susceptible dogs. The following study was designed to determine whether immunization with an inactivated $\mathrm{CCV}$ vaccine would protect dogs from clinical disease induced using this model. Dogs $(n=13)$ were vaccinated with an inactivated $C C V$ vaccine. Vaccinates and controls $(n=5)$ were orally inoculated with virulent $\mathrm{CCV}$ virus and treated with dexamethasone on days $0,2,4$, and 6 after virus challenge. Control dogs developed clinical signs including diarrhea, dehydration, anorexia, depression, and nasal and ocular discharge. Diarrhea was noted in $80 \%$ of the controls and $60 \%$ progressed to a severe watery or bloody diarrhea that persisted for multiple days. Conversely, only $2 / 13$ (15\%) vaccinates developed mild diarrhea and none developed bloody diarrhea. The control dogs averaged 10.8 days of diarrhea compared to 1.4 days for vaccinates over the 21 day observation period. In addition to reduced clinical signs, the number of days of virus shedding and the level of CCV in feces was different for controls ( $100 \%$ shed virus) and vaccinates ( $38 \%$ shed virus). This study demonstrates that vaccination with an inactivated CCV vaccine can significantly reduce not only viral replication, but the occurrence of clinical disease following a virulent $\mathrm{CCV}$ infection.
\end{abstract}

\section{INTRODUCTION}

Coronavirus was first recognized as a disease agent in dogs in 1971 when it was isolated during an epizootic of diarrhea in Germany. ${ }^{\prime}$ Canine coronavirus (CCV) was subsequently isolated from outbreaks of canine viral enteritis in the United States in $1978^{2}$ and serological surveys have identified the prevalence of coronavirus exposure in dogs in numerous countries. ${ }^{3-6}$ Although the disease noted in field cases of canine coronavirus infection may be severe, ${ }^{1}$ it has been difficult to induce significant clinical signs using 
experimental models. ${ }^{7,8}$ In this report, enhanced clinical disease was induced when glucocorticoids were administered in conjunction with CCV inoculation of dogs. This laboratory model was used to demonstrate the effectiveness of an inactivated vaccine in preventing clinical disease in dogs.

\section{MATERIALS AND METHODS}

Animals. Mixed breed dogs, 16-20 weeks in age and of both sexes were used. Dogs were confirmed to lack serum antibodies against canine coronavirus (by serum neutralization assay as previously described ${ }^{8}$ ), as an indication of no prior virus exposure, before initiation of the study.

Vaccine. A commercially available inactivated CCV vaccine (Duramune ${ }^{\circledR} \mathrm{CvK}$, Fort Dodge Laboratories, Fort Dodge, IA) was used.

Viruses. The I-71 isolate ${ }^{\mathrm{l}}$ and the SA4 isolate (American BioResearch, Seymour, TN) of $\mathrm{CCV}$ at low culture passage were used for challenge. Viruses were grown on Crandell Feline Kidney (CRFK) cells and pooled in approximately equal proportions to yield a challenge pool. The challenge pool had a titer of $10^{63} \mathrm{TCID}_{50} / \mathrm{mL}$ on CRFK cells.

Detection of Virus Shedding. A minimum of 0.2 grams of feces was collected from each dog daily from -1 to 21 days after CCV inoculation. Fecal material was diluted with $1.8 \mathrm{~mL}$ of Hanks Balanced Salt Solution containing gentamicin $(100 \mu \mathrm{g} / \mathrm{mL})$. Fecal suspensions were vortexed and clarified by centrifugation $(500 \mathrm{x} \mathrm{g}, 20$ minutes). Supernatant fluids were inoculated onto Crandell Feline Kidney (CRFK) cells and incubated for 7 days a $37^{\circ} \mathrm{C}$. Virus was detected by direct immunofluorescence using a fluorescein conjugated antibody (American BioResearch, Seymour, TN).

Experimental Design. Dogs were divided into vaccinated $(n=13)$ and control $(n=5)$ groups. Vaccinated dogs were immunized with two doses of vaccine given 21 days apart (Serial \#147179A for first vaccination and Serial \#147177A for second vaccination) by either subcutaneous injection in the scruff of the neck $(n=6)$ or intramuscular injection in a rear leg $(n=7)$. Fourteen days after the second vaccination, immunized and control dogs were inoculated orally with $6 \mathrm{~mL}$ of the CCV challenge pool $\left(10^{71} \mathrm{TCID}_{50}\right.$ per dog). Dogs were injected intramuscularly with $2 \mathrm{mg}$ of dexamethasone (Azium, ${ }^{\circledR}$ Schering Plough, Kenilworth, NJ; average of $0.12 \mathrm{mg} / \mathrm{kg}$ of body weight) on the day of virus inoculation and again on days 2,4 , and 6 after challenge. Dogs were monitored for fever (rectal temperature), weight, and clinical signs of disease from -3 to 21 days after CCV inoculation. Clinical signs were scored as outlined in Table 1. Clinical signs of disease in vaccinated animals were compared to controls using Mann Whitney Ranked Sum Analysis (Statview II, Abacus Concepts, Inc.) using a Macintosh PC.

\section{RESULTS}

Dogs were vaccinated with two doses of an adjuvanted, inactivated CCV vaccine administered by intramuscular $(n=6)$ or subcutaneous $(n=7)$ injection, 21 days apart. Fourteen days after the second immunization, vaccinated and control dogs were challenged orally with a pool of two virulent canine coronaviruses. A mildly immunosuppressive dose of dexamethasone was administered on the day of CCV challenge and 2, 4, and 6 days later. Clinical signs of CCV-induced disease including diarrhea, depression, dehydration, inappetance, nasal discharge, and ocular discharge were noted in control dogs between 2 and 21 days after virus inoculation. In previous studies, dexamethasone administration in the absence of $\mathrm{CCV}$ inoculation did not result in these types of clinical signs in dogs. ${ }^{9}$ Canine coronavirus was detected in fecal samples from all control dogs with a duration of 1 to 6 days. Virus shedding was detected between days 3 and 8 after virus inoculation and preceded 
Table 1. Scoring of clinical signs following virulent $\mathrm{CCV}$ inoculation

\begin{tabular}{llc}
\hline Sign & & Score/Observation \\
\hline Fever & $103.5-103.9^{\circ} \mathrm{F}$ & 1 point \\
& $104.0-104.9^{\circ} \mathrm{F}$ & 2 points \\
& $\geq 105.0^{\circ} \mathrm{F}$ & 4 points \\
Diarrhea & Soft, Mucous & 1 point \\
& Watery & 2 points \\
& Bloody & 3 points \\
Dehydration & & 1 point \\
Inappetance & & 1 point \\
Nasal/Ocular Discharge & & 1 point \\
$\geq 10 \%$ Weight Loss & & 3 points \\
\hline
\end{tabular}

the days of peak clinical signs (days 5 through 12, see Figure 1). Significant diarrhea was noted in $80 \%$ of the control dogs and progressed to severe, watery diarrhea in three out of five of these animals. No significant weight loss was noted in control dogs during the observation period after CCV challenge.

Vaccinated animals, on the other hand, showed few clinical signs of disease (Figure 1). CCV shedding was only noted in 5/13 (38\%) vaccinated animals compared to $5 / 5(100 \%)$ controls. When clinical signs in vaccinates were compared to controls (Figure 2), statistically significant reductions were noted in the occurrence of dehydration $(100 \%$ reduction, $\mathrm{p}<0.001)$, diarrhea scores $(90 \%$ reduction, $\mathrm{p}<0.02)$, number of days of diarrhea $(86 \%$ reduction, $\mathrm{p}=0.02)$, and number of days of virus shedding $(87 \%$ reduction, $p=0.003)$. Vaccinates had fewer signs of inappetance, nasal discharge, and ocular discharge than controls, although changes in these clinical signs were not statistically significant. The average cumulative clinical score for

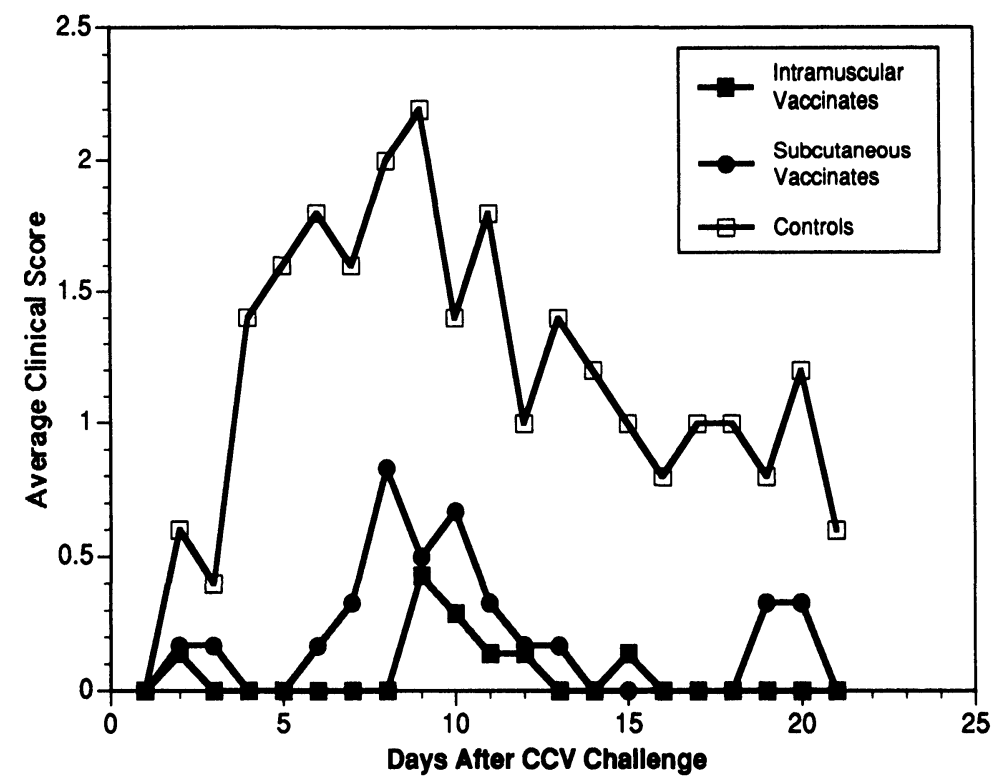

Figure 1. Average daily clinical scores following CCV challenge. The average daily clinical score (calculated as shown in Table 1) for vaccinated and control animals is shown for the 21 day period following CCV inoculation. 


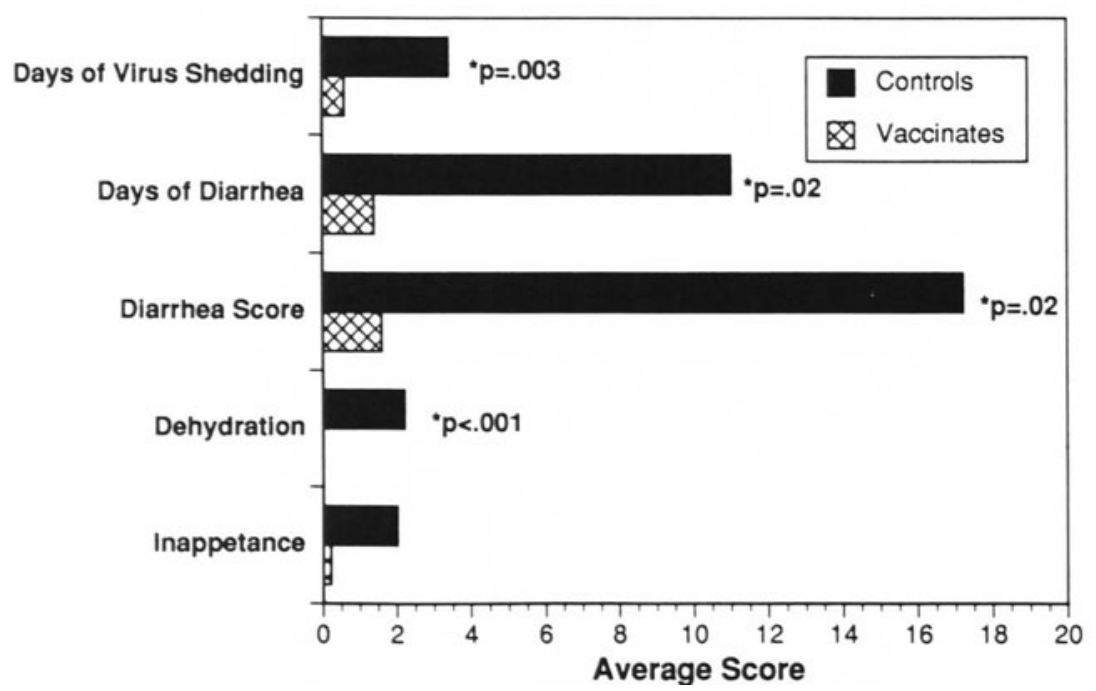

Figure 2. Comparison of vaccinates and controls for key clinical signs following CCV challenge The average scores (calculated as shown in Table 1) for vaccinates as compared to controls are shown for key clinical signs following CCV challenge including. Inappetance, dehydration, diarrhea The average number of days of diarrhea and virus shedding are also shown for vaccinates and controls *Statistical significance values are shown for vaccinates compared to controls as determıned by Mann Whitney Ranked Sum Analysis

intramuscular vaccinates was 1.3 and for subcutaneous vaccinates was 4.2 , which were both significantly lower than the 24.8 average score in controls (Figure 3 ).

\section{DISCUSSION}

Canıne coronavirus was discovered as the causative agent of gastroenteritis in dogs. ${ }^{1}$ However, the importance of this pathogen has been questioned because of difficulty in

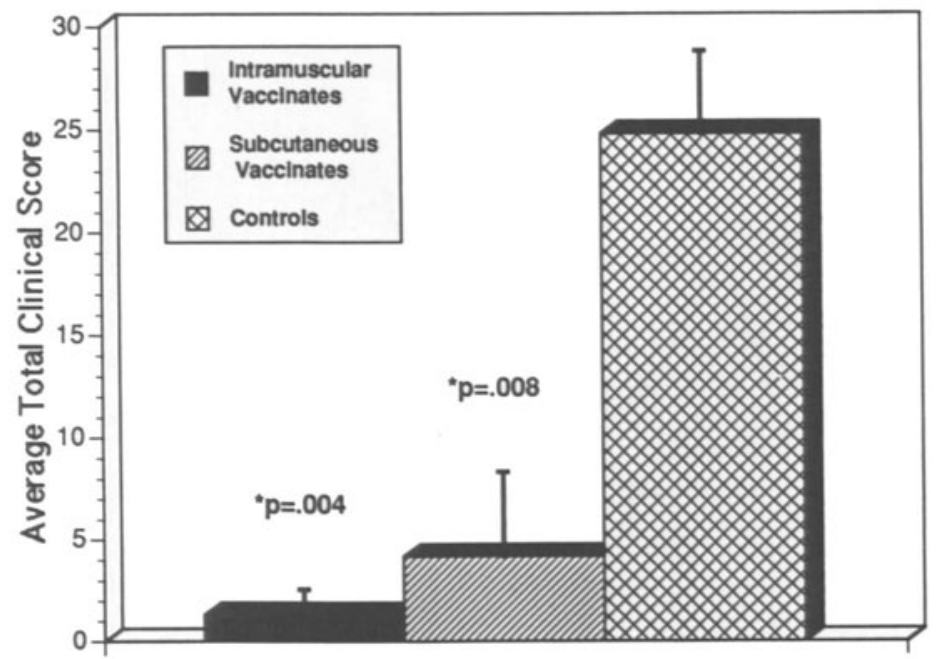

Figure 3. Average total clinical scores following CCV challenge The cumulative clinical score for each animal was summed and the group averages $( \pm S E)$ are shown for intramuscular vaccinates, subcutaneous vaccinates, and controls *Statistical significance values are shown for vaccinates compared to controls as determined by Mann Whitney Ranked Sum Analysıs 
reproducing clinical disease in dogs under experimental conditions. Conditions causing stress in dogs, such as poor nutrition or overcrowding, and concurrent infections with other agents have been hypothesized to contribute to the severity of disease that has been documented with CCV in field cases. In support of the latter hypothesis, experimental inoculation of dogs with $\mathrm{CCV}$ in combination with canine parvovirus has been shown to be fatal under conditions where either virus by itself caused a self-limiting disease. ${ }^{10}$ Because canine parvovirus can infect cells of the immune system, this study also suggested that $\mathrm{CCV}$-induced disease may be augmented by immunosuppression.

In the study reported here, clinical disease was induced in dogs inoculated with CCV and the immunosuppressive drug dexamethasone. The clinical signs observed in this study included diarrhea, dehydration, depression, inappetance, nasal discharge and ocular discharge. In previous studies, where dexamethasone treatment was used in the absence of CCV inoculation, such clinical signs were not observed in dogs. ${ }^{9}$ The clinical disease found in control dogs in this study resembles the findings of other investigators who have inoculated young puppies ( $<6$ weeks old) with CCV alone. ${ }^{1,8}$ However, this is the first report where significant clinical signs have been induced in older dogs. This model of experimental CCV infection supports the hypothesis that stress, which also can cause immunosuppression, may play an important role in the severity of CCV infection under natural conditions.

Previous vaccine studies have relied on the demonstration of reduced intestinal infection and CCV shedding as parameters of vaccine efficacy. ${ }^{11}$ In this case, diminished infection rates were assumed to predict a reduced disease incidence in vaccinated animals. In the study reported here, the ability of an inactivated CCV vaccine to prevent disease was directly assessed. Using this CCV infection model, it was found that immunization resulted in a reduction in the occurrence and severity of diarrhea, inappetance, dehydration, depression, nasal discharge, ocular discharge, and virus shedding when controls were compared to vaccinates after CCV challenge. Therefore, this study shows that an inactivated vaccine is capable of inducing an immune response which will protect against clinical signs caused by CCV. This experimental model may provide a means to more fully assess the mechanism of immune protection against $\mathrm{CCV}$ infection and disease.

\section{REFERENCES}

1 Bınn, LN , Lazar E C , Keenan K P, Huxsoll D L, Marchwickı R H, Strano A J 1974 Recovery and characterization of a coronavirus from military dogs with diarrhea Proceedings of the 78th Meetıng of the U S Animal Health Association, pp359-366

2 Appel M, Meunier P, Pollock R, et al 1980 Canıne Viral Enteritıs Canıne Pract 7:22-36

3 Miller J, Evermann J, Ott, R 1980 Immunofluorescence test for canıne coronavirus and parvovirus West Vet 18 14-19

4 Tuchıya, K, Horımoto, T, Azetka, M, Takahashı, E, Konıshı, S 1991 Enzyme-lınked ımmunosorbent assay for the detection of canine coronavirus and its antıbody in dogs Vet Microbiol 26 41-51

5 Herbst, W, Zhang, X M, and Schliesser, T 1988 The seroprevalence of coronavirus infections in the dog in West Germany Berl Munch Tierarztl Wochenschr 101 381-383

6 Rımmelzwann, G F, Groen, J , Egberınk, H , Borst, G H, UtydeHaag, F G, Osterhaus, A D 1991 The use of enzyme-linked immunosorbent assay systems for serology and antigen detection in parvovirus, coronavirus and rotavirus infections in dogs in the Netherlands Vet Microbiol 26 25-40

7 Appel M 1987 Canıne coronavirus In Virus Infections of Carnivores Ed M Appel, Elsevier, New York, pp 115-122

8 Tennant, B J , Gaskell, R M , Kelly, D F, Carter, S D 1991 Canıne coronavirus infectıon in the dog following oronasal inoculation Res Vet $\mathrm{Sc}$ 51 11-18

9 Wasmoen, T L , Sebrıng, R W, Blumer, B M , Chavez, L G, Chu, H-J , Acree, W M 1992 Examınation of Koch's postulates for Borrelıa burgdorferl as the causatıve agent of limb/joint dysfunction in dogs with borreliosis J Am Vet Med Assoc $201412-418$ 
10 Appel, M J G 1988 Does canıne coronavirus augment the effects of subsequent parvovirus infection? Vet Med 83 360-366

11 Acree, W M , Edwards, B , Black, J W Canıne Coronavirus Vaccine International Application Published under the Patent Cooperation Treaty, International publication date 3rd January 1985, number WO 85/00014, World Intellectual Property Organisation 